\title{
OPTIMIZATION TECHNIQUES IN POWER SYSTEM: REVIEW
}

\author{
Ms. Frie Ayalew \\ Department of Electrical and \\ Computer Engineering \\ Addis Ababa Science and \\ Technology University \\ Addis Ababa, Ethiopia
}

\author{
Ms. Seada Hussen \\ Department of Electrical and \\ Computer Engineering \\ Addis Ababa Science and \\ Technology University \\ Addis Ababa, Ethiopia
}

\author{
Dr. Gopi Krishna Pasam \\ Department of Electrical and \\ Computer Engineering \\ Addis Ababa Science and \\ Technology University \\ Addis Ababa, Ethiopia
}

\begin{abstract}
Power systems are very large and complex, it can be influenced by many unexpected events this makes Power system optimization problems difficult to solve, hence methods for solving these problems ought to be, an active research topic. This review presents an overview of important mathematical optimization methods those are Unconstrained optimization approaches Nonlinear programming (NLP), Linear programming (LP), Quadratic programming (QP), Generalized reduced gradient method, Newton method, Network flow programming (NFP), Mixed-integer programming (MIP), Interior point (IP) methods and Artificial intelligence (AI) techniques such as Artificial Neural Network (ANN), fuzzy logic,Genetic Algorithm (GA), Particle Swarm Optimization (PSO),Tabu Search (TS) algorithm, etc. and Hybrid artificial intelligent techniques are discussed. And also applications of optimization techniques have been discussed. Finally classification, application area, observation, conclusion, and recommendation for future research work will be forwarded.
\end{abstract}

Keywords - NLP, QP, AI, Hybrid AI, PSO, GA,

etc.

\section{INTRODUCTION}

It's known that Power systems are very large, complex and geographically distributed. Therefore, to take the advantages in simplifying the problem and its implementation it is necessary to utilize most efficient optimization methods. Related to the power system operation numerous activities require optimum searching techniques $\mathrm{K}$ wang Lee. Et al. (2008) Many researchers working with optimization techniques to solve economic issue, reliability, quality, optimal load flow, protection, cost and soon. D. Hore. et al. (2013) presented about Artificial Intelligence methods such as GA, PSO, BFO, ANN that used for Optimal Power Flow and economic load dispatch problem.
K. Liu. et al. (2006) combined adaptive genetic algorithm with Simulated annealing was presented to solve active power loss minimization. J. Lu. et al. (2010) presented the techniques of GA and PSO are combined to obtain good particles from genetic algorithm for the initial population input of PSO. A. Badar. et al. (2014) Improved or hybrid artificial intelligence methods have been discussed after Genetic algorithm, Particle Swarm Optimization, Ant Colony Optimization, Tabu Search, Simulated Annealing and Differential Evolution presented. Binitha S. et al. (2012) presents an overview of biologically inspired optimization algorithms which grouped by the biological and application areas. O.P. Malik. (2004) the possibility of implementing an adapting controller using different approach has been presented. G. Hwang. et al. (2007) to determine the optimal PID gain Craziness based Particle Swarm Optimization (CRPSO) and binary coded GA methods has been proposed. V. Mukherjee. et al. (2008) propose the hierarchical fuzzy PSS to enhance stability.

M. Caner. et al. (2008). was used Bacteria Foraging Optimization (BFO) technique. S.P. Ghoshal. et al. (2009) to design PSS A robust adaptive fuzzy controller proposed. A. Badar. et al. (2014) has been presented an overview of different artificial intelligence (AI) optimization techniques used in power optimization problems and a Hybrid or improved AI techniques. Yuvaraja T. et al. (2015) was presented the performance of the implemented PSO algorithm for solving an optimization problem that is related to improving the quality of the power supply in a Microgrid scenario. S. Khajeh. et al. (2016) was presented Genetic algorithm for Optimal Reconfiguration of Power Distribution Systems in radial 33 buses distribution network. S. H. Kiran.et al. (2016) has been presented Particle Swarm Optimization (PSO) and Artificial Bee Colony (ABC) with Hybrid-Genetic Algorithm (H-GA) for determination of sizing of FACTS.

A. K. Khamees. et al. (2017) proposed shuffled frog leaping algorithm and grey wolf optimizer, to solve the 


\section{International Journal of Engineering Applied Sciences and Technology, 2019 \\ Vol. 3, Issue 10, ISSN No. 2455-2143, Pages 8-16 \\ Published Online February 2019 in IJEAST (http://www.ijeast.com)}

optimal power flow problem in electrical power system. C. M. K. Sivalingam. et al. (2017). Interactive artificial bee colony (IABC) was proposed to obtain reactive power optimization after comparing the results obtained from IPSO, QPSO, ABCO, and IABCO. Ö.P. Akkaş. et al. (2018) propose genetic algorithm to minimize fuel cost tested on 6generator test system by ignoring line losses. S. Dean. et al. (2018) proposed a multi-stage procedure, called Coarse-ID control, that estimates a model from a few experimental trials, estimates the error in that model with respect to the truth, and then designs a controller using both the model. C.T.M. Clack .et al. (2015) shows that linear programming techniques can represent an electrical power system from a high-level without undue complication brought on by moving to mixed integer or nonlinear programming. Different optimization techniques with its invention year shown in Fig. 1:

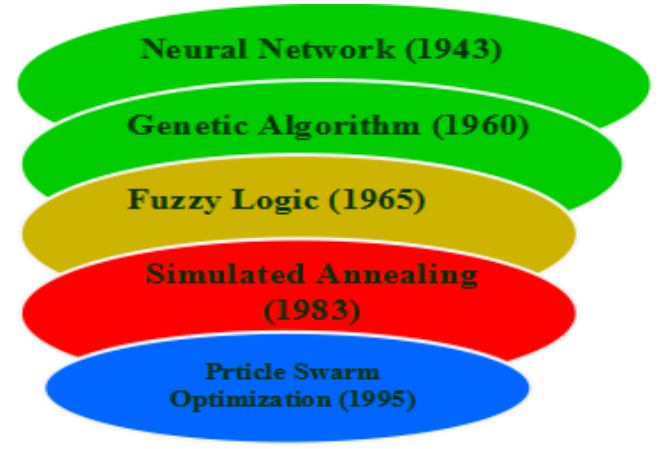

Fig. 1: Some optimization methods with its invention year

\section{OVERVIEW OF OPTIMIZATION TECHINIQUES}

The main objective of optimization is to minimize undesirable things (e.g. cost, energy loss, errors, etc.) or maximize desirable things (e.g. profit, quality, efficiency, etc.) since its mathematical model, subject to some constraints. Optimization is a commonly encountered mathematical problem in all engineering disciplines. It literally means finding the best possible/desirable solution. Optimization problems are wide ranging and numerous, hence methods for solving these problems. From the view of optimization, the various techniques including traditional and modern optimization methods, which have been developed to solve power system operation, control and planing problems.

\section{CLASSIFICATION OF OPTIMIZATION TECHNIQUES}

Basically optimization techniques are classified into three groups. Which are traditional method, Artificial intelligent method and hybrid artificial intelligent techniques.

\section{A. Traditional Method}

Traditional methods are optimality mathematical rigorous in some algorithms and problems can be formulated to take advantage of the existing sparsity techniques applicable to large-scale power systems. Those methods are Unconstrained optimization approaches Nonlinear programming (NLP), Linear programming (LP), Quadratic programming (QP), Generalized reduced gradient method, Newton method, Network flow programming (NFP), Mixedinteger programming (MIP), Interior point (IP) methods and soon[50-56].

\section{$B$. Artificial Intelligent Techniques}

Artificial Intelligence (AI) techniques proved to be effective tools to resolve many power system problems and that they could be more effective when properly joined together with conventional mathematical approaches [43-46]. These techniques are Artificial Neural Network (ANN), Fuzzy logic, intelligent optimization, genetic algorithm, particle swarm optimization and soon. Different PSSs were proposed based on these AI techniques $[2,5,7,12,16,29,61,64,67,95]$.

\section{Hybrid AI Techniques}

Power system problems may effectively solved by the strengths and capabilities or fit the assumptions of a single AI technique. One approach to deal with these complex real world problems is to integrate the two or more techniques in order to combine their strengths and overcome each others weaknesses to generate hybrid solutions [29]. Those techniques are Fuzzy neural network systems Fuzzy/ neural/expert/genetic systems, Simulated annealing with, fuzzy/genetic/expert systems and soon [21-28]. 


\section{International Journal of Engineering Applied Sciences and Technology, 2019 \\ Vol. 3, Issue 10, ISSN No. 2455-2143, Pages 8-16 \\ Published Online February 2019 in IJEAST (http://www.ijeast.com)}

Traditional method [50 - 56]

$\checkmark$ Unconstrained \&constrained[62]

$\checkmark$ Linear \& non linear Programming[20,50,52,55]

$\checkmark$ Quadratic Programming

$\checkmark$ Newton Method

$\checkmark$ Interior Programming

$\checkmark$ Weighting objectives

$\checkmark$ Generalized Reduced Gradient Method

\section{Artificial Intelligent Method} $[2,5,7,12,16,29,61,64,67]$

$\checkmark$ Genetic Algorithm $[14,38,40,41,58,59,94,95]$

$\checkmark$ Particle Swarm Optimization $[26,30,34,39,44,45,63,68,70,9$ 6]

$\checkmark$ Simulated Annealing[71,72]

$\checkmark$ Tabu Search[65]

$\checkmark$ Ant Colony[56]

$\checkmark$ Neural Network[47,73-92]

$\checkmark$ Fuzzy Set[8,10,11,43,46]

$\checkmark$ Pareto Multi Objective
Hybrid Artificial Intelligent Method[3,4,9,18,13,21-25, 27, $28,33,35,36,57,60,66,69,93,97]$

$\checkmark$ Heuristic[1,17,32,37]

$\checkmark$ Fuzzy Expert/Genetic

$\checkmark$ Particle Swarm/PSO

$\checkmark$ Fuzzy/PSO/GA

$\checkmark$ Neural/expert/genetic systems

$\checkmark$ Simulated annealing with,fuzzy/genetic/expert systems

Fig. 1: Classification of optimization techniques and related works

\section{APPLICATION AREAS OF OPTIMIZATION TECHNIQUES}

Optimization techniques are applicable on different power system stages such as generation, transmission, distribution and customers side for minimizing different problems, and its percentage applicability as shown Fig. 3: The application areas are shown in table 1 and its classification with optimization problem is shown in Fig. 2:

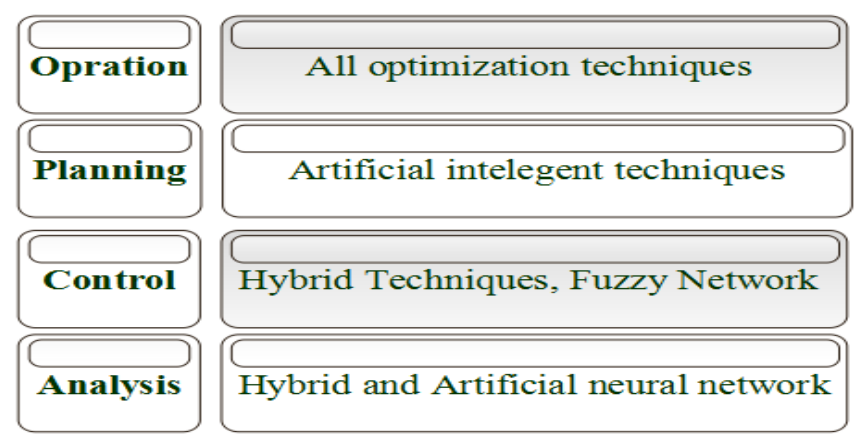

Fig. 2: Classification of optimization methods with its application depend on table 1.

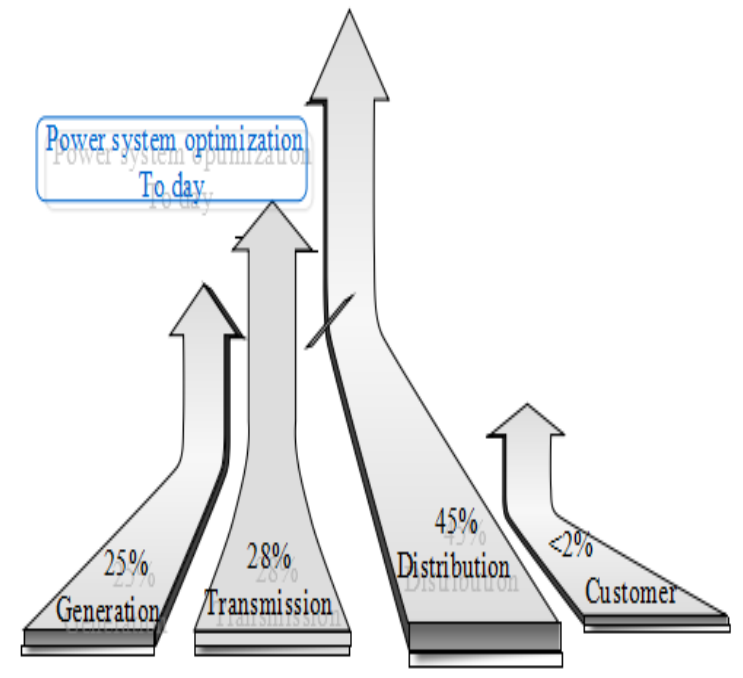

Fig.3: Optimization techniques percentage applicability on power systems today 


\section{International Journal of Engineering Applied Sciences and Technology, 2019 \\ Vol. 3, Issue 10, ISSN No. 2455-2143, Pages 8-16 \\ Published Online February 2019 in IJEAST (http://www.ijeast.com)}

Table 1: Application of optimization techniques and related works.

\begin{tabular}{|c|c|c|c|}
\hline $\begin{array}{l}\text { Operation }[2,5,12-19,26,27,31-34,38- \\
42,45,46,50-66,68-71,81-90,96,97]\end{array}$ & $\begin{array}{l}\text { Control }[3,4,6,7,9,10,36 \text {, } \\
43,44,79,92]\end{array}$ & $\begin{array}{l}\text { Planning [20-23,25,28,35,67, } \\
72-78,80,91,94,95]\end{array}$ & Analysis $[8,11,24,47,93]$ \\
\hline $\begin{array}{l}\checkmark \text { Constrained load flow } \\
\checkmark \text { Unit commitment / economic dispatch } \\
\checkmark \text { Optimal power flow } \\
\checkmark \text { Voltage/Var and loss reduction } \\
\checkmark \text { Dynamic load modeling } \\
\checkmark \text { Short-Term load forecast } \\
\checkmark \text { Network reconfiguration and load } \\
\checkmark \text { reduction } \\
\checkmark \text { Market operations, etc. } \\
\checkmark \text { Fault diagnosis } \\
\checkmark \text { Stability/Transient stability } \\
\checkmark \text { Static and dynamic security assessment }\end{array}$ & 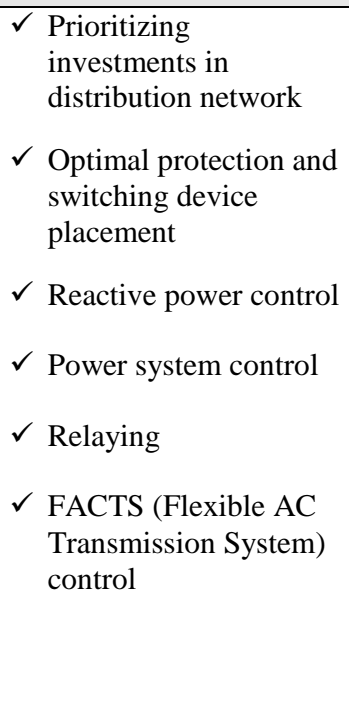 & $\begin{array}{l}\checkmark \text { Reactive power planning } \\
\checkmark \text { Generation expansion } \\
\text { planning } \\
\checkmark \text { Generation and distribution } \\
\checkmark \text { Generation scheduling } \\
\checkmark \text { Maintenance scheduling } \\
\checkmark \text { Power mix planning } \\
\checkmark \text { Capacitor placement/ } \\
\quad \text { voltage control } \\
\checkmark \text { Hydro scheduling } \\
\checkmark \text { Long term load foretasting }\end{array}$ & $\begin{array}{l}\checkmark \text { Power system stabilizer } \\
\checkmark \text { Power plant operation } \\
\text { optimizer }\end{array}$ \\
\hline
\end{tabular}

V. ADVANTAGES AND DISADVANTAGES ARTIFICIAL INTELLIGENT TECHNIQUES OVER TRADITIONAL METHODS

\section{A. Advantages}

> Artificial intelligent methods applicable for smart grid because of it's modernity.

$>$ Genetic algorithm needs only rough information of the objective function and places no restriction such as differentiability and convexity on the objective function.

$>$ Genetic algorithm works with a set of solutions from one generation to the next, and not a single solution, thus making it less likely to converge on local minima.

$>$ Genetic algorithm the solutions of developed are randomly based on the probability rate of the genetic operators such as mutation and crossover; the initial solutions thus would not dictate the search direction of GA.

$>$ Fuzzy logic is more accurately represents the operational constraints of power systems and Fuzzified constraints are softer than traditional constraints

$>$ Ant Colony Search technique has been mainly used in finding the shortest route for transmission network

$>$ The advantages of simulated annealing are, general applicability to deal with arbitrary systems and cost functions its ability to refine optimal solution, and its simplicity of implementation even for complex problems.

\section{B. Disadvantages}

$>$ Poor computational of the Ant Colony Search is the main drawback of this technique.

$>$ The major drawback of simulated annealing is repeated annealing.

$>$ Genetic algorithm method is requires tremendously high time.

\section{OBSERVATIONS}

* Some authors work with hybrid artificial intelligent technique's for better performance of all optimization problem.

* Others indicating Swarm intelligence have more potential in power system analysis and they are also the most recent in the field of computational intelligence technique.

* Many researcher indicates that simulated annealing are selected for arbitrary system, cost functions, refine optimal solution and simplicity of implementation complex problem.

* Artificial intelligence problems require use of knowledge bases to store human knowledge, operator judgment particularly in practical solutions, experience gained over a period of time, characterization by network uncertainty, load variations, etc.

- Power system optimization is aimed at improvements in more areas than cost: reliability, efficiency, economics, environmental friendliness, security. 


\section{CONCLUSION AND RECOMMENDATION}

\section{A. Conclusion}

Power system planning and operation raises many important decision making problems, which are generally stated as large scale, nonlinear, mixed integer continuous, and non-convex stochastic and or robust optimization problems. Many researcher works with different optimization techniques but still the issue is not solved. Using artificial intelligent techniques is the better choice compared with traditional methods but for any power system optimization problem hybrid artificial intelligent optimization techniques are still not comparable. Generally this review indicates which optimization techniques appropriate for power system problem such as profit, quality, efficiency and soon.

\section{B. Recommendation}

* It is recommended that using PSO and BFO based techniques are faster and more advance method for finding optimum load flow solutions.

* Using Improved or hybrid artificial intelligence methods are recommended to combine the better performance characteristics of various search methods .

* GWO is the most useful technique for solving the complicated OPF problem.

* IABCO was one among various optimization methods that produces better results. Maintenance of voltage profile, reduction of power loss, and optimization of reactive power has been facilitated by the algorithm.

* Usage of meta-heuristic genetic algorithms is recommended to find the optimal location for placing the FACTS device.

\section{REFERENCES}

[1] Kwang Lee, and Elsharkawi. (2008). modern heuristic optimization techniques.,Wiley.

[2] Debirupa Hore, NM.Lokhande (2013). Computational Analysis of Different Artificial Intelligence Based Optimization Techniques for Optimal Power Flow and Economic Load Dispatch Problem,.Inational Journal of Computers \& Technology, Volume 4, Jan -Feb.

[3] Keyan Liu, Wanxing Sheng; Yunhua Li,(2006). Research on Reactive Power Optimization based on Adaptive Genetic Simulated Annealing Algorithm, International Conference on Power System Technology, Chongqing, pp: $1-6$.

[4] Jingui Lu, Li Zhang; Hong Yang,(2010). Combining strategy of genetic algorithm and particle swarm algorithm for reactive power optimization, ,
International Conference on Electrical and Control Engineering (ICECE-2010), Wuhan, pp: 3613 - 3616.

[5] Altaf Badar, Dr. B.S. Umre, Dr. A. S; Junghare. (2014). Study of Artificial Intelligence Optimization Techniques applied to Active Power Loss Minimization, Journal of Electrical and Electronics Engineering,2 014, PP 39-45.

[6] Binitha S, and S Siva Sathya, (2012). A Survey of Bio inspired Optimization Algorithm. International Journal of Soft Computing and Engineering (IJSCE), Volume-2.

[7] O.P. Malik.(2004). Amalgamation of adaptive control and ai techniques:applications to generator excitation control. Annual Reviews in Control, vol. 28, pp. 97106.

[8] G. Hwang, D. Kim, J. Lee, and Y. An. (2008). Design of fuzzy power system stabilizer using adaptive evolutionary algorithm, Engineering Applications of Artificial Intelligence, vol. 21, pp. 86-96.

[9] V. Mukherjee, and S.P.(2007). Ghoshal. Intelligent particle swarm optimized fuzzy pid controller for AVR system, Electrical Power Systems Research, vol. 77, no. 12, pp. 689-1698.

[10] M. Caner, N. Umurkan, S. Tokat, S.V. Ustun. (2008) Determination of optimal hierarchical fuzzy controller parameters according to loadingcondition with ANN", Expert Systems with Applications, vol. 34, pp. 26502655.

[11] S.P. Ghoshal, A. Chatterjee, and V. Mukherjee. (2009). Bio-inspired fuzzy logic based tuning of power system stabilizer, Expert Systems with Applications, vol. 36, pp. 9281-9292.

[12] Altaf Badar, Dr. B.S. Umre, Dr. A. S. Junghare. (2014). Study of Artificial Intelligence Optimization Techniques applied to Active Power Loss Minimization, Journal ofElectrical and Electronics Engineering.

[13] Yuvaraja T, Ramya K, Gopinath M. (2015). Artificial Intelligence and Particle Swarm Optimization Algorithm Foroptimization Problem In Microgrids", Vol 8, Issue 3, 2015.

[14] Sina Khajeh Ahmad Attari, Mahmoud Reza Shakarami, Farhad Namdari. (2016). Pareto Optimal Reconfiguration of Power Distribution Systems with Load Uncertainty and Recloser Placement Simultaneousely Using a Genetic Algorithm Based on NSGA-II", Indonesian Journal of Electrical Engineering and Computer Science, Vol. 1, March 2016, pp. 419 430.

[15] S. Harish Kiran, Subhransu Sekhar Dash, C. Subramani. (2016). Performance of two modified optimization techniques for power system voltage stability problems, Alexandria Engineering Journal.

[16] Amr K. Khamees, Ahmed El-Rafei, N. M. Badra, Almoataz Y. Abdelaziz. (2017). Solution of optimal power flow using evolutionary-based algorithms, 


\section{International Journal of Engineering Applied Sciences and Technology, 2019 \\ Vol. 3, Issue 10, ISSN No. 2455-2143, Pages 8-16 \\ Published Online February 2019 in IJEAST (http://www.ijeast.com)}

International Journal of Engineering, Science and Technology, Vol. 9, 201 7, pp. 55-68.

[17] Chandragupta Mauryan Kuppamuthu Sivalingan, Subramanian Ramachandran , Purrnimaa Shiva Sakthi Rajamani. (2017). Reactive p ower optimization in a p ower system network through metaheuristic algorithms, Turkish Journal of Electrical Engineering \& Computer Sciences.

[18] Ö.P. Akkaş, E. Çam, İ. Eke, Y. Arıkan. (2018). New Optimization Algorithms for Application to Environmental Economic Load Dispatch in Power Systems, Electrica, vol. 18, no: 2, pp. 133-142.

[19] Sarah Dean, Horia Mania, Nikolai Matni, Benjamin Recht, and Stephen Tu. (2018) On the Sample Complexity of the Linear Quadratic Regulator, California Institute of Technology, December 17.

[20] C.T.M. Clack , Y. Xie , A.E. MacDonald. (2015). Linear programming techniques for developing an optimal electrical system including high-voltage direct-current transmission and storage, Electrical Power and Energy Systems.

[21] P.K. Dash, A.C. Liew, and S. Rahman.(1996) Fuzzy Neural Network and Fuzzy Expert Systems for Load Forecasting, IEE Proceedings - Generation Transmission and Distribution, 143(1): 106-114.

[22] K.H. Kim, K. J. Park, K. J. Hwang, and S.H. Kim..(2005). Implementation of Hybrid Short Term Load Forecasting using Artificial Neural Networks, International Journal of Emerging Electric Power Systems, Vol. 2, 2005. DOI: 10.2202/1553-779X.1021.

[23] Y. M. Park, J. B. Park, and J. R. Won. (1997). A Hybrid Genetic Algorithm/Dynamic Programming Approach To Optimal Long-Term Generation Expansion Planning", Int. Journal of Electrical Power and Energy Systems, 20(4): 295-30.

[24] A. Afzalin and D.A. (2000). Linkens. Training of Neuro Fuzzy Power System Stabilizer using Genetic Algorithm, Int. Journal of Electrical Power and Energy Systems, 22(2): 93-102, 2000.

[25] W.S. Jwo, C.W. Liu, C.C. Liu, and Y.T. Hsiao. (1995). Hybrid Expert System and Simulated Annealing Approach to Optimal Reactive Power Planning, IEE Proceedings, Generation Transmission and Distribution, 142(4): 381-385, 1995.

[26] F. Benhamida, Y. Salhi, I. Ziane, S. Souag, R. Belhachem and A. Bendaoud. (2013). A PSO algorithm for the economic load dispatch including a renewable wind energy, 3rd International Conference on Systems and Control, pp. 1104-1109.

[27] K.P. Wong and S.Y.W. Wong. (1997). Hybrid Genetic/Simulated Annealing to Short Term Multiple Fuel-Constrained Generation Scheduling, IEEE Trans. Power Systems, 12(2):776-784.
[28] H. Kim, K. Nara, and M. Gen. (2004). A Method for Maintenance Scheduling using GA Combined with SA" Computers and Industrial Engineering, 27(4): 477- 480.

[29] K. Wardwick, A. Ekwue, and R. Aggarwal. .(1997). Artificial Intelligence Techniques in Power Systems, IEE, London, UK.

[30] Dan Cristian, Constantin Barbulescu, Stefan Kilyeni, Vasile Popescu, (2013), Particle Swarm Optimization Techniques-Power Systems Applications, Proc. of 6th IEEE Int. Conf. on Human System Interaction (HIS).

[31] Rekha R, Kannan G. (2013). A Comparative Analysis on Reactive Power Optimization Using Various Techniques in Deregulated Power System", Proc. of IEEE 2013, Int. Conf. on Energy Efficient Technologies for Sustainability (ICEETS).

[32] S. A. Jumaat, I.Musirin, M. M. Othman and H. Mokhlis. (2011). A Hybrid MetaHeuristics Optimization Technique for Loss Minimization and Cluster Identification in Power System Network, Proc. of 2011.

[33] Himmat Singh, Laxmi Srivastava. (2016). Optimal VAR control for real power loss minimization and voltage stability improvement using Hybrid Multi-Swarm PSO, Proc. of 2016 IEEE Int. Conf. on Circuit, Power and Computing Technologies [ICCPCT].

[34] J.Praveen, Dr. B.Srinivasa Rao. (2016). Multi Objective Optimization for Optimal Power Flow with IPFC using PSO, Proc. of 2016 3rd Int. Conf. on Electrical Energy Systems.

[35] R. Aggarwal and Y.H. Song. (1997). Fuzzy Logic and Neural Networks in Generation and Distribution. Power Technology International, Spring Issue, 39-45.

[36] P.K. Dash, T.S. Sidhu, and H.S. Gill. (2000). A Novel Fuzzy Neural Based Distance-Relaying Scheme, IEEE Trans. Power Delivery, 15(3): 895-901.

[37] Y.H. Song and M.R. Irving. (2001). Optimization Methods for Electric Power Systems, Part 2, Heuristic Optimization Methods, IEE Power Engineering Journal, 15(3): 151-160.

[38] J. Nanda, R. Badri Narayanan. (2001). Application of genetic algorithm to economic load dispatch with Lineflow constraints, pp 723-729.

[39] Amita Mahor, Vishnu Prasad, Saroj Rangnekar. (2009). Economic dispatch using particle swarm optimization: A review, Renewable and Sustainable Energy Reviews 13, pp 2134-2141.

[40] R. Hugh, R. Palma, E. Cura, and C. Silva. (1996). Economically Adapted Transmission System in Open Access Schemes - Application of Genetic Algorithm. IEEE Trans. Power Systems, 11(3): 1427-1440, 1996.

[41] K. Nithiyananthan, V. Ramachandran. (2011). Enhanced Genetic Algorithm Based Model for Power System, Vol I.

[42] R. Vijay. (2012). Intelligent Bacterial Foraging Optimization Technique to Economic Load Dispatch 


\section{International Journal of Engineering Applied Sciences and Technology, 2019 \\ Vol. 3, Issue 10, ISSN No. 2455-2143, Pages 8-16 \\ Published Online February 2019 in IJEAST (http://www.ijeast.com)}

Problem, International Journal of Soft Computing and Engineering (IJSCE) ISSN: 2231-2307, Volume-2, Issue-2.

[43] N. He, R. Liu , and D. Xu. (2005). The study of upfc fuzzy control with selfadjustable factor, IEEE/PES Transmission and Distribution Conference \& Exhibition: Asia and Pacific Dalian, China, pp. 1-5.

[44] G.K. Venayagamoorthy. (2005). Optimal control parameters for a UPFC in a multimachine using pso," Intelligent Systems Application to Power Systems.

[45] A.T. Al-Awami, Y.L. Abdel-Magid, and M.A. Abido. (2007). A particleswarm-based approach of power system stability enhancement withunified power flow controller, Electric Power and Energy Systems, vol. 29, pp. 251-259.

[46] E.M. Gouveia, and M.A. Matos. (2009). Symmetric ac fuzzy power flow model," European journal of Operation Research, vol. 197, pp. 1012- 1019.

[47] R. Segal, A. Sharma, and M.L. Kothari. (2004). A selftuning power system stabilizer based on artificial neural network", Electrical Power and Energy Systems, vol. 26, pp. 423- 430.

[48] P. Panciatici, M.C. Campi, S. Garatti, S.H. Low, D.K. Molzahn, A.X. Sun, L. Wehenkel. (2014). Advanced optimization methods for power systems", 18th Power Systems Computation Conference Wroclaw, Poland August 18-22.

[49] Binitha S, S Siva Sathya. (2012). A Survey of Bio inspired Optimization Algorithms", International Journal of Soft Computing and Engineering (IJSCE), Volume-2.

[50] Dr. Firas Mohammed Tuaimah , Montather Fadhil Meteb. (2014). A Linear Programming Method Based Optimal Power Flow Problem for Iraqi Extra High Voltage Grid (EHV), Journal of Engineering, Volume 20.

[51] Jizhong Zho, (2009). Optimization Of Power System Operation", Institute Of Electrical and Electronics Engineers John Wiley \& Sons, Inc., Hoboken, New Jersey,2009.

[52] Tareq A. Al-Muhawesh\&Isa S. Qamber. (2008). The Established Mega Watt Linear ProgrammingBased Optimal Power Flow Model.

[53] Giacomoni A.M.\&Wollenberg B.F. (2010). Linear Programming Optimal Power Flow Utilizing", Saudi Arabia, Elsevier, Volume 33, Issue 1, pp. 12-21.

[54] Morgan M.G. and S. Talukdar. (1996 ). A Trust Region Method, IEEE, North American Power Symposium (NAPS) .,Nurturing R\&D, IEEE Spectrum, Vol. 33, No.7, July pp. 32- 33.

[55] Ye Tao,A. (2009). Sequential Linear Programming Algorithm for Security-Constrained Optimal Power Flow, IEEE, North American Power Symposium (NAPS) Conference.
[56] W. Yamany, A. Tharwat, M. F. Hassanin, T. Gaber, A. E. Hassanien and T. H. Kim. (2015). A New Multi-layer Perceptrons Trainer Based on Ant Lion Optimization Algorithm, Fourth International Conference on Information Science and Industrial Applications (ISI), Busan, 2015, pp. 40-45.

[57] Guo-Li Zhang, Hai-Yan Lu, Geng-Yin Li and GuangQuan Zhang,. (2005). Dynamic economic load dispatch using hybrid genetic algorithm and the method of fuzzy number ranking, 2005nInternational Conference on Machine Learning and Cybernetics, Guangzhou, China, pp. 2472-2477 Vol. 4.

[58] K. Asano, M. Nakatsuka and T. Kumano. (2009). Dynamic Economic Load Dispatch by Calculus of Variation and Genetic Algorithm Considering Ramp Rate, 2009 15th International Conference on Intelligent System Applications to Power Systems, Curitiba, pp. 1 6.

[59] C. L. Chiang,, (2007). Genetic-based algorithm for power economic load dispatch," in IET Generation, Transmission \& Distribution, vol.1, no. 2, pp. 261 -269.

[60] A.Derghal and N. Golea. (2014). Genetic algorithm for solving large practical fuzzy economic load dispatch with prohibited operating zones, 2014 International Renewable and Sustainable Energy Conference (IRSEC), Ouarzazate, pp. 469-474.

[61] J.Eswari, Dr.S.Jeyadevi. (2014). “An Evolutionary Approach for Optimal Citing and Sizing of Micro-Grid in Radial Distribution Systems" International Journal of Engineering Trends and Technology (IJETT), Volume 11.

[62] Niknam, T., Narimani, M., Aghaei, J., Tabatabaei, S., \& Nayeripour, M. (2011). Modified honey bee mating optimisation to solve dynamic optimal power flow considering generator constraints, IET Generation, Transmission \& Distribution, Vol. 5, No. 10, pp. 989100.

[63] Praveen, J., \& Rao, B. S. (2016). Multi-objective optimization for optimal power flow with IPFC using PSO”, Electrical Energy Systems (ICEES).

[64] Sayah, S., \& Zehar, K. (2008). Modified differential evolution algorithm for optimal power flow with nonsmooth cost functions" Energy Conversion and Management, Vol. 49, No. 11, pp. 3036-3042.

[65] Senthil, K., \& Manikandan, K., (2008). Economic thermal power dispatch with emission constraint and valve point effect loading using improved tabu search algorithm" International Journal of Computer Applications, Vol. 3, No. 9, pp. 6-11.

[66] Uman, M., Rao, M. V. G., Hanumaiah, A., \& Rajesh, K. (2016). Solution of economic load dispatch problem in power system using Lambda Iteration and back propagation neural network methods"International 


\section{International Journal of Engineering Applied Sciences and Technology, 2019 \\ Vol. 3, Issue 10, ISSN No. 2455-2143, Pages 8-16 \\ Published Online February 2019 in IJEAST (http://www.ijeast.com)}

Journal on Electrical Engineering and Informatics, Vol. 8, No. 2, p. 347.

[67] R.A. Gallego, A.B. Alves, A. Monticelli, and R. Romero. (1997). Parallel Simulated Annealing Applied to Long Term Transmission Network Expansion Planning. IEEE Trans. Power Systems, 12(1): 181-188..

[68] H. Cao et al.. (2016). Economic dispatch of micro-grid based on improved particle-swarm optimization algorithm, 2016 North American Power Symposium (NAPS), Denver, CO, pp. 1 -6.

[69] B. Das and T. K. Sengupta. (2015). Economic load dispatch using PSO and TLBO," Michael Faraday IET International Summit 2015,Kolkata,, pp. 212-219.

[70] D. Maity, S. Baneijee, C. K. Chanda and S. Samanta, (2016). Implementation of MRPSO techniques on economic load dispatch problem considering various generator constraints," 2016 10th International Conference on Intelligent Systems and Control (ISCO), Coimbatore, pp. 1 -6.

[71] H.T. Yang, P.C. Yang, and C.L. Huang.. (1997). A Parallel Algorithm Approach to Solving the Unit Commitment Problem: Implementation on the Transputer Network, . IEEE Trans. Power Systems, 12(2): 661-668.

[72] T. Satoh and K. Nara. (1991). Maintenance Scheduling by Using Simulated Annealing Method, IEEE Trans. Power Systems, 6(2) 850-857.

[73] D.D. Highly and T.J. Hilmes. (1993). Load Forecasting by ANN, IEEE Computer Applications in Power, 6(3) 10-15, 1993.

[74] D. Park. (1991). Electric Load Forecasting Using an Artificial Neural Network, IEEE Trans. Power Systems, 6(2): 442-449, 1991.

[75] N.I. Santoso and O.T. Tan. (1990). Neural-Net Based Real-Time Control of Capacitors Installed on Distribution Systems". IEEE Trans. Power Delivery, 5(1): 266-272, 1990.

[76] M.J. Short, C.K. Hui, J.F. Macqeen, and A.O. Ekwue. (1994). Application of Artificial Neural Network for NGC Voltage Collapse Monitoring, CIGRE Symposium, Paris, Paper 28-205.

[77] Y.H. Song, H.B. Wan, and A.T. Johns. Kohonen. (1997). Neural Network Based Approach to Voltage Weak Buses Areas Identification, IEE Proceedings- Generation Transmission Distribution, 144(3):340-344.

[78] A.D. Roy and S.K. Goswami. (1996). Development of Artificial Neural Networks for Solving Capacitor Control Problem in Distribution Network, Proc. $9^{\text {th }}$ National Power Systems Conference, IIT Kanpur (India), 413-416.

[79] Z. Gu and D.T. Rizy. (1996). Neural Network for Combined Control of Capacitance Banks and Voltage Regulators in Distribution Systems". IEEE Trans. Power Systems, 11(4): 1921-1928.
[80] E.L. da Silva, H.A. Gill, and J.M. Areiza. (2000). Transmission Network Expansion Planning Under an Improved Genetic Algorithm". IEEE Trans. Power Systems, 15(3): 1168-1175.

[81] P.S. Kulkarni, A.G. Kothari, and D.P. Kothari. (2000). Combined Economic Dispatch Unit using Economic Improved Back Propagation Neural Network., Electric Machines and Power Systems, 28(8): 31-44.

[82] D. Singh and S.P. Singh. (2001). ANN Based Short Term Load Forecasting, Institution of Engineers (India), 82(3): 155-160, 2001.

[83] H. Mori and A. Yuithara. (2001). Deterministic Annealing for ANN-Based Short-Term Load Forecasting, IEEE Trans. Power Systems, 16(3): 545551.

[84] H.S. Hippert, C.E. Pedeira, and H. Hamadanizadeh. (2001). Neural Network for Short-Term Load Forecasting." IEEE Trans. Power Systems, 16(1): 44-55.

[85] S. Krunic, I. Krcmar, and N. Rajakovic. (2000). An Improved Neural Network Approach for Short-Term Load Forecasting. Electric Machines and Power Systems, 28(8): 703-722.

[86] M.M. Tawfik and M.M. Morcos. (2001). ANN-Based Technique for Estimating Fault Location on Transmission Lines Using Prony Method", IEEE Trans. Power Delivery, 16(2): 219-224.

[87] H.A. Darwish and A.M.I. Taalab. (2001). Development to Implementation of ANN Based Fault Diagnosis Scheme for Generator Winding Protection, IEEE Trans. Power Delivery, 16(2): 200-207.

[88] Z. Chen and J.C. Mann. (2000). Artificial Neural Network Approach to Single Ended Fault Locator for Transmission Lines, IEEE Trans. Power Systems, 15(1): 370-375.

[89] W.L. Chan, A.T.P. So and L.L. Lia. (2000). Initial Application of Artificial Neural Network to Load Flow Analysis, IEE Proceedings- Generation Transmission and Distribution, 147(6): 361-366.

[90] S. Ghosh and B.H. Chowdhury. (1996). Security Constrained Optimal Rescheduling of Real Power using Hopfield Neural Network. IEEE Trans. Power Systems, 11(4): 1743-1748.

[91] R. Naresh and J. Sharma. (2000). Hydro System Scheduling Using ANN Approach, IEEE Trans. Power Systems, 15(1): 388-395.

[92] X.Z. Dai, D. He, L.L. Fan, N.H. Li, and H. Chen. 1999). (Improved ANN Alpha Th-Order Inverse TCSC Controller for Enhancing Power System Transient Stability, IEE Proceedings- Generation Transmission and Distribution, 146(6): 550-556.

[93] S. Madnani.. (2000). Radial Basis Function (RBF) Network Adaptive Power System Stabilizer". IEEE Trans. on Power Systems, 15(2):722-727. 
[94] J.B. Park, Y.M. Park, and K.Y. Lee. (2000). An Improved Genetic Algorithm for Transmission Network Expansion Planning". IEEE Trans. Power Systems, 15(3): 916-922.

[95] M. Delfanti, G.P. Granelli, P. Marannino, and M. Montagna.. (2000). Optimal Capacitor Placement using Deterministic and Genetic Algorithms". IEEE Trans. on Energy Conversion, 15(3): 1041-1046.

[96] S. B. Nejad, S. H. Elyas, A. Khamseh, I. N. Moghaddam and M. Karrari. (2012). Hybrid CLONAL selection algorithm with PSO for valve-point Economic load Dispatch," 2012 16th IEEE Mediterranean Electrotechnical Conference, YasmineHammamet, pp. 1147-1150.

[97] D. Santra, A. Mukherjee, K. Sarker and D. Chatterjee. (2016). Hybrid PSO-ACO algorithm to solve economic load dispatch problem with transmission loss for small scale power system," 2016 International Conference on Intelligent Control Power and Instrumentation (ICICPI), Kolkata, pp. 226-230. 